\title{
O encontro com os signos artísticos do cinema produzindo movimentos aberrantes nas redes de conversação com professores e professoras
}

\section{The encounter with the artistic signs of cinema producing aberrant movements in conversation networks with teachers}

\section{El encuentro con los signos artísticos del cine produciendo movimientos aberrantes en redes de conversación con profesores}

Tânia Mara Zanotti Guerra Frizzera Delboni ${ }^{1}$

Carlos Pereira de Melo²

DOI: http://dx.doi.org/10.20435/serie-estudos.v26i58.1583

\begin{abstract}
Resumo: Apresenta uma experimentação provocada em processos de formação inventiva - de professores e professoras da escola pública - no encontro com os signos artísticos do cinema, no intuito de produzir movimentos aberrantes em redes de conversações. Argumenta que o pensamento - por meio do encontro com os signos artísticos - pode ser constrangido ao estranhamento, ao desconhecido, instaurando processos de subjetivação e criação de mundos nos quais outros pensamentos são possíveis. O campo problemático, delineado nos encontros com os signos artísticos e corpos e fluxos e intensidades, pode ser assim enunciado: de que modo os movimentos aberrantes fazem liberar a potência da vida, engendrando modos outros de subjetivação? Apresenta a cartografia como aporte teórico-metodológico para acompanhar as redes de conversações que fazem proliferar afetos e afecções na constituição de movimentos aberrantes do pensamento no encontro com os signos artísticos. Deleuze, Guattari, Lapoujade e Carvalho são os intercessores convidados para essa composição com professores e professoras de duas escolas públicas de Educação Infantil da Serra, ES. Afirma os encontros de formação inventiva de professores e professoras como experimentação, nos quais os percursos, tempos e fluxos são inventados, compartilhados e, por serem intensivos, reverberam movimentos aberrantes do pensamento que dão a falar currículos, docências, aprendizagens.
\end{abstract}

Palavras-chave: currículos; formação continuada; signos artísticos.

\footnotetext{
${ }^{1}$ Universidade Federal do Espírito Santo (UFES), Vitória, Espírito Santo, Brasil.

${ }^{2}$ Secretaria Municipal de Educação de Serra; Secretaria Municipal de Cariacica, Espírito Santo, Brasil.
} 


\begin{abstract}
It presents an experimentation provoked in processes of inventive formation - of public school teachers - in the encounter with the artistic signs of cinema in order to produce aberrant movements in conversational networks. It argues that thought - from the encounter with artistic signs - can be constrained to estrangement, to the unknown, establishing processes of subjectivation and creation of worlds in which other thoughts are possible. The problematic field, delineated from the encounters with artistic signs and bodies and flows, and intensities, can be stated as follows: how do aberrant movements release the power of life, engendering other modes of subjectivation? It presents cartography as a theoretical-methodological contribution to follow the networks of conversations that make fondness and affections proliferate in the constitution of aberrant movements of thought in the encounter with artistic signs. Deleuze, Guattari, Lapoujade, and Carvalho are the invited intercessors for this composition, together with teachers from two public schools of Early Childhood Education in Serra, ES. It affirms the encounters of inventive formation of teachers and teachers as experimentation, in which paths, times, and flows are invented, shared, and because they are intensive, they reverberate aberrant movements of thought that give voice to curricula, teaching, learning.
\end{abstract}

Keywords: curriculum; teacher training; artistic signs.

Resumen: Presenta una experimentación provocada en procesos de formación inventiva - de profesores de escuelas públicas - en el encuentro con los signos artísticos del cine para producir movimientos aberrantes en redes conversacionales. Argumenta que el pensamiento - desde el encuentro con los signos artísticos - puede constreñirse al extrañamiento, a lo desconocido, estableciendo procesos de subjetivación y creación de mundos en los que otros pensamientos son posibles. El campo problemático, delineado a partir de los encuentros con signos y cuerpos y flujos e intensidades artísticos, se puede plantear de la siguiente manera: ¿cómo los movimientos aberrantes liberan el poder de la vida engendrando otros modos de subjetivación? Presenta la cartografía como un aporte teórico-metodológico para seguir las redes de conversaciones que hacen proliferar los afectos y las afecciones en la constitución de movimientos aberrantes del pensamiento en el encuentro con los signos artísticos. Deleuze, Guattari, Lapoujade y Carvalho son los intercesores invitados para esta composición, junto con profesores de dos escuelas públicas de Educación Infantil de Serra, ES. Afirma los encuentros de formación inventiva de docentes y docentes como experimentación, en los que se inventan, se comparten caminos, tiempos y flujos y, por ser intensivos, reverberan movimientos aberrantes de pensamiento que dan voz a los currículos, la enseñanza, el aprendizaje.

Palabras clave: currículo; formación continua; signos artísticos.

\title{
1 OS MOVIMENTOS ABERRANTES...
}

Para Lapoujade (2015, p. 9), o que interessa a Deleuze são os movimentos aberrantes, pois "A filosofia de Deleuze se apresenta como uma filosofia dos movimentos aberrantes ou dos movimentos 'forçados'" - daqueles que provocam uma ruptura, uma quebra, uma brecha, um deslocamento - forçando, impelindo e engendrando a experimentação de um novo pensamento, um novo percurso, 
O encontro com os signos artísticos do cinema produzindo movimentos aberrantes nas redes de conversação com professores e professoras

um novo traço. "Pensar é criar, não há outra criação, mas criar é, antes de tudo, engendrar, 'pensar' no pensamento" (DELEUZE, 2018, p. 201).

A filosofia de Deleuze, referindo-se aos movimentos aberrantes como potência do pensamento e como potência política, convoca-nos a fazer do pensamento uma máquina de guerra, pois "[...] pensar, para Deleuze, sempre foi concebido como um ato guerreiro" (LAPOUJADE, 2015, p. 23). Como máquina de guerra, ${ }^{3}$ esses movimentos provocam "[...] uma ruptura, uma brecha que quebra uma continuidade [...], forçando-a a uma espécie de viagem através de um 'a mais de realidade' intenso e assustador, seguindo linhas de fuga nas quais se precipitam natureza e história, organismo e espírito" (LAPOUJADE, 2015, p. 10-1). Assim, em Deleuze, a vida,

[...] como confirmam os movimentos aberrantes, não se restringe a produzir organismos, tampouco se limita à forma orgânica. Esses movimentos atestam uma força inorgânica da vida que atravessa o organismo vivo indiferente a sua integridade. Daí o caráter perturbador do vitalismo de Deleuze, indissociável da morte e dos perigos que ela faz correr. A vida implica a morte de algo em nós para liberar as potências. É preciso prudência para morrer de vida. (TÓTORA, 2017, p. 109).

O encontro com a filosofia de Deleuze no grupo de pesquisa do qual fazemos parte tem-nos provocado a instaurar movimentos outros de pensamento, de experimentação, para afirmar a força dos movimentos aberrantes, aquilo que a vida faz morrer em nós, para liberar suas potências. Nesse sentido, partimos para pensar a força dos encontros (mesmo que de forma remota) com professores e professoras para potencializar o pensamento e engendrar - numa aposta ético-estético-política - movimentos de fazer "[...] morrer tudo o que não é necessário" (LAPOUJADE, 2015, p. 22), afirmando a vida em sua potência.

Apresentamos aqui uma experimentação provocada em processos de formação continuada - de professores e professoras de duas escolas públicas de Educação Infantil do município da Serra, ES - no encontro com os signos artísticos do cinema, no intuito de produzir movimentos aberrantes em redes

\footnotetext{
${ }^{3}$ Fazer do pensamento uma máquina de guerra é pôr o pensamento em relação imediata com o inusitado, com o impensável, com o diferente. Para Deleuze e Guattari (2012, p. 48), “[...] não é de modo algum uma outra imagem que se oporia à imagem inspirada no aparelho de Estado. Ao contrário, é a força que destrói a imagem e suas cópias, o modelo e suas reproduções, toda possibilidade de subordinar o pensamento a um modelo".
} 
de conversações (CARVALHO, 2009). Os encontros formativos ocorreram no período de setembro a dezembro de 2020, de forma remota, nos turnos matutino e vespertino, e contaram com a participação de 75 professores e professoras. Apostamos na cartografia como aporte teórico-metodológico para acompanhar as redes de conversação, fazendo proliferar afetos e afecções na constituição de movimentos aberrantes do pensamento, no encontro com os signos artísticos. Os intercessores teóricos convidados para essa composição coletiva são Deleuze, Guattari, Lapoujade e Carvalho, com professores e professoras participantes do processo de formação continuada.

Inspirados em Deleuze, a intenção do processo formativo foi entrar em relação com os signos artísticos do cinema para fazer proliferar movimentos desterritorializantes, em busca de outros territórios existenciais, para instaurar novas realidades, novas experimentações, para fazer do pensamento uma potência nômade, engrenagem de uma máquina de guerra.

O campo problemático que instigou essa experimentação foi delineado mediante os encontros com os signos artísticos e corpos e fluxos e intensidades: de que modo os movimentos aberrantes fazem liberar a potência da vida, engendrando modos outros de subjetivação? Com base nessa problematização, outras foram se constituindo e ampliando o nosso campo de investigação: como produzir uma experimentação vital, instaurando conexões, fluxos, agenciamentos? O que precisamos combater (ou fazer morrer o que não é necessário) para afirmar a vida em sua potência? O que os movimentos aberrantes, de tão intensivos, reverberam sobre currículos, docências, infâncias, aprendizagens, enfim, sobre a vida?

Argumentamos que o pensamento - mediante o encontro com os signos artísticos - pode ser constrangido ao estranhamento, ao desconhecido, instaurando processos de subjetivação e criação de mundos nos quais outros pensamentos são possíveis. Em meio aos encontros compartilhados, professores e professoras produzem, por meio dos afetos e afecções, fluxos imanentes de vida coletiva e fazem fluir "[...] uma experimentação que contamina o pensamento e, por sua vez, contagia a terra pelo pensamento" (TÓTORA, 2017, p. 110).

Trazemos, nesta escrita, a experimentação provocada em um encontro com professores e professoras no qual usamos, como elemento disparador para as redes de conversação, os signos artísticos do cinema a partir do curta Comme un éléphant dans un magasin de porcelaine (2017). Os signos da arte são 
apresentados como força para romper com as representações, impulsionando outros possíveis, imagens outras do pensamento e, assim, produzir nova temporalidade no território da Educação Infantil e, nele, compartilhar outros mundos que carregamos nesses tempos de fazer experiências inventivas de formação em tempos de pandemia. Buscamos a potência dos signos da arte no encontro com as imagens-cinema e professores e professoras para produzir, por meio de redes de conversação, movimentos aberrantes que promovem outros modos de invenção de mundos possíveis.

Dessa maneira, essa escrita-experimentação foi delineada com base em três movimentos: no primeiro, trazemos uma conversa com Deleuze (2003) sobre os signos, por meio de sua obra "Proust e os signos"; em seguida, apresentamos os afetos e as afecções produzidos no encontro com o curta Comme un éléphant dans un magasin de porcelaine; e, finalmente, buscamos articular as reverberações provocadas, não para concluir a escrita, mas para provocar mais ressonâncias no pensamento.

\section{OS SIGNOS ARTÍSTICOS COMO POSSIBILIDADE DE IMAGENS OUTRAS DO PENSAMENTO}

O nosso ponto de partida é a concepção deleuziana sobre os signos, por meio da obra de Marcel Proust, em seu livro "Proust e os signos". Deleuze apresenta a interpretação dos signos como aquilo que nos coloca num processo de aprendizado, mediante a ideia de que os signos nos forçam a pensar mais do que representam em si mesmos algo a ser conhecido.

Aprender diz respeito essencialmente aos signos. Os signos são objeto de um aprendizado temporal, não de um saber abstrato. Aprender é, de início, considerar uma matéria, um objeto, um ser, como se emitissem signos a serem decifrados, interpretados. Não existe aprendiz que não seja 'egiptólogo' de alguma coisa. Alguém só se torna marceneiro tornando-se sensível aos signos da madeira, e médico tornando-se sensível aos signos da doença. A vocação é sempre uma predestinação com relação a signos. Tudo que nos ensina alguma coisa emite signos, todo ato de aprender é uma interpretação de signos ou de hieróglifos. A obra de Proust é baseada não na exposição da memória, mas no aprendizado dos signos. (DELEUZE, 2003, p. 4).

Inspirado na literatura de Proust, Deleuze nos propõe uma primeira ideia de signos, que são os signos mundanos. São signos que assumem o lugar de uma 
suposta realidade, fazendo com que ela se torne dependente deles e se organize com base no que eles impõem. Diferentemente de uma ideia de signos que representam o mundo, os signos mundanos constroem o mundo perceptível, artificialmente, quase como se soubéssemos, de modo antecipado, o que os encontros com ele significam. "O signo mundano não remete a alguma coisa; ele a 'substitui', pretende valer por seu sentido. Antecipa ação e pensamento, anula pensamento e ação, e se declara suficiente" (DELEUZE, 2003, p. 6). Para Deleuze, o aprendizado seria imperfeito e até mesmo impossível se não passasse por eles. São signos vazios, mas essa vacuidade Ihes confere uma perfeição ritual, como que um formalismo que não se encontrará em outro lugar. Somente os signos mundanos são capazes de provocar uma espécie de exaltação nervosa, que exprime sobre nós o efeito das pessoas que sabem produzi-los.

Ainda em Proust, Deleuze captura outro tipo de signo. São os signos do amor.

Os signos amorosos não são como os signos mundanos: não são signos vazios, que substituem o pensamento e a ação; são signos mentirosos que não podem dirigir-se a nós senão escondendo o que exprimem, isto é, a origem dos mundos desconhecidos, das ações e dos pensamentos desconhecidos que lhes dão sentido. Eles não suscitam uma exaltação nervosa superficial, mas o sofrimento de um aprofundamento. (DELEUZE, 2003, p. 9).

Esses signos, diferentemente do que acontece com os signos mundanos, não substituem uma suposta realidade, mas trazem consigo a certeza de que algo está escondido; daí a importância da interpretação e da busca incessante por sua natureza. Aqui podemos pensar que Deleuze, entre os signos mundanos e os signos amorosos, opera progressivamente por meio de um nível de incerteza em relação aos signos.

Trata-se de uma aparição que se configura como um dado real dos signos mundanos, e, adiante, vamos à incerteza e à inquietude provocada pelos signos do amor. Se, por um lado, temos um signo que nos faz saber pelo hábito, que nos faz indagar "como agir no encontro com ele?", por outro, temos os signos amorosos cuja incerteza nos faz procurar algo para além do aparente. Nesse sentido, o signo torna-se cada vez mais uma abertura para aquele que se encontra com ele.

Temos ainda um terceiro tipo de signo: os signos sensíveis, os quais, por sua vez, provocariam algo parecido com uma espécie de exaltação pela correspondência com aquilo que designa. É uma qualidade sensível que nos proporciona uma 
estranha alegria, ao mesmo tempo que nos transmite uma espécie de imperativo. Uma vez experimentada, a qualidade não aparece mais como uma propriedade do objeto que a tem no momento, mas como o signo de um objeto completamente diferente, que devemos tentar decifrar por meio de um esforço sempre sujeito ao fracasso. Tudo se passa como se a qualidade envolvesse, mantivesse aprisionada a alma de um objeto diferente daquele que ela agora designa (DELEUZE, 2003).

Essa conduta revela algo de diferente do que inicialmente nos causou alegria pela sua imaginada adequação, ou seja, o significado fugiu ao que possibilitou o conforto. Podemos entender os signos sensíveis como um momento de decepção, na medida em que tínhamos, antes, a convenção segura dos signos mundanos; depois, modificada pela desconfiança em relação aos signos amorosos; e, agora, metamorfoseada em alegria pela retomada de que os signos sensíveis simultaneamente proporcionam desilusão pelo seu caráter de deslocamento do significado.

Nesse sentido, é importante dizer que as qualidades dos signos sensíveis, mesmo bem interpretadas, não são ainda em si mesmas signos suficientes. Não são mais signos vazios, provocando-nos uma exaltação artificial, como os signos mundanos, tampouco não são signos enganadores que nos fazem sofrer, como os do amor, cujo verdadeiro sentido nos provoca um sofrimento cada vez maior. São signos verídicos que imediatamente nos dão uma sensação de alegria incomum, signos plenos, afirmativos e alegres (DELEUZE, 2003).

Assim, o que Deleuze nos permite fazer com os signos e ir além coloca-nos diante do problema da arte.

Ora, o mundo da Arte é o último mundo dos signos; e esses signos, como que desmaterializados, encontram seu sentido numa essência ideal. Desde então, o mundo revelado da Arte reage sobre todos os outros, principalmente sobre os signos sensíveis; ele os integra, dá-lhes o colorido de um sentido estético e penetra no que eles tinham ainda de opaco (DELEUZE, 2003, p. 13).

No mundo da arte, os signos são aqueles que mais desorientam do que representam, põem-nos em movimento de criação. Assim, os signos artísticos são aqueles que vão dar o que pensar, ou seja, violentar o nosso pensamento e nos colocar em movimento de criação de significado, mesmo que provisório ou incerto. São signos que estão mais para a descontinuidade, para criar um mundo novo do que encadear e adaptar o conhecimento com a realidade. Aqui retomamos os 
movimentos aberrantes do pensamento produzidos no encontro com os signos artísticos. O pensamento é entendido aqui como "[...] um vento que nos impele, uma série de rajadas e de abalos" (DELEUZE, 1992, p. 118). Os movimentos aberrantes "[...] nos transportam para o que há de impensável no pensamento, de invivível na vida, de imemorial na memória [...]" (LAPOUJADE, 2015, p. 19).

Nesse sentido, os signos artísticos são signos imateriais, mas que podem, num mesmo instante, criar novas materialidades. "É por esta razão que todos os signos convergem para a arte; todos os aprendizados, pelas mais diversas vias, são aprendizados inconscientes da própria arte. No nível mais profundo, o essencial está nos signos da arte" (DELEUZE, 2003, p. 13). Assim, o nosso interesse é pensar a inventividade que perpassa o nosso cotidiano e permeia o funcionamento cognitivo na relação com o pensamento de Deleuze, que nos convida à adoção da arte como perspectiva, como um ponto de vista a partir do qual a aprendizagem é problematizada (KASTRUP, 2001).

\section{AS POTÊNCIAS DOS SIGNOS DA ARTE COM AS IMAGENS-CINEMA NO ENCONTRO COM PROFESSORES E PROFESSORAS EM MOVIMENTOS DE FORMAÇÃO INVENTIVA}

É possível pensarmos espontaneamente ou precisamos de algo externo para nos forçar a pensar? O que nos dá a pensar o encontro com as imagens-cinema em movimentos de formação continuada com professores e professoras da Educação Infantil? Pensamos os movimentos cinematográficos e sua profusão de imagens e de signos como um campo de experimentação do pensamento e, assim, o que nos leva a pensar é o encontro com o problema, para fazer emergir movimentos outros.

A noção de formação inventiva de professores e professoras que defendemos aqui está na convocação de Dias (2009, p. 164), para quem o problema da formação convida-nos a "[...] uma outra noção e habita o conhecer pela problematização que tensiona a própria formação".

A formação de professores é pensada por aquilo que move os encontros, no meio dos quais há tensão e possibilidade entre os diferentes modos e formas de pensar e de fazer o conhecer. O desafio é tomar o conhecer como invenção de problemas, abrindo-se para as imprevisibilidades e pequenas invenções que emergem dos contextos de formação. Dias (2009, p. 164). 
Assim, se a imagem-cinema é a arte do pensamento, tomamos o curta Comme un éléphant dans un magasin de porcelaine como disparador na produção de algo que nos inquieta e nos coloca em movimento pensante nos encontros de formação com professores e professoras. Provocamos encontros com as imagens-cinema não para falar sobre os curtas, mas para conversar sobre as afecções que as imagens causam em nosso corpo-pensamento.

As imagens foram usadas para provocar, para possibilitar um deslocamento no pensamento, para nos tirar do lugar e causar movimentos aberrantes que nos arrancam de nós mesmos, para fazer com que não atenhamos à nossa vida naquilo que ela tem de pessoal, mas de impessoal que ela permite atingir, ver, criar e sentir (LAPOUJADE, 2015).

\section{MOVIMENTOS DE CONVERSAÇÃO COM O CURTA COMME UN ÉLÉPHANT DANS UN MAGASIN DE PORCELAINE}

Imagem 1 - Na loja de porcelanas

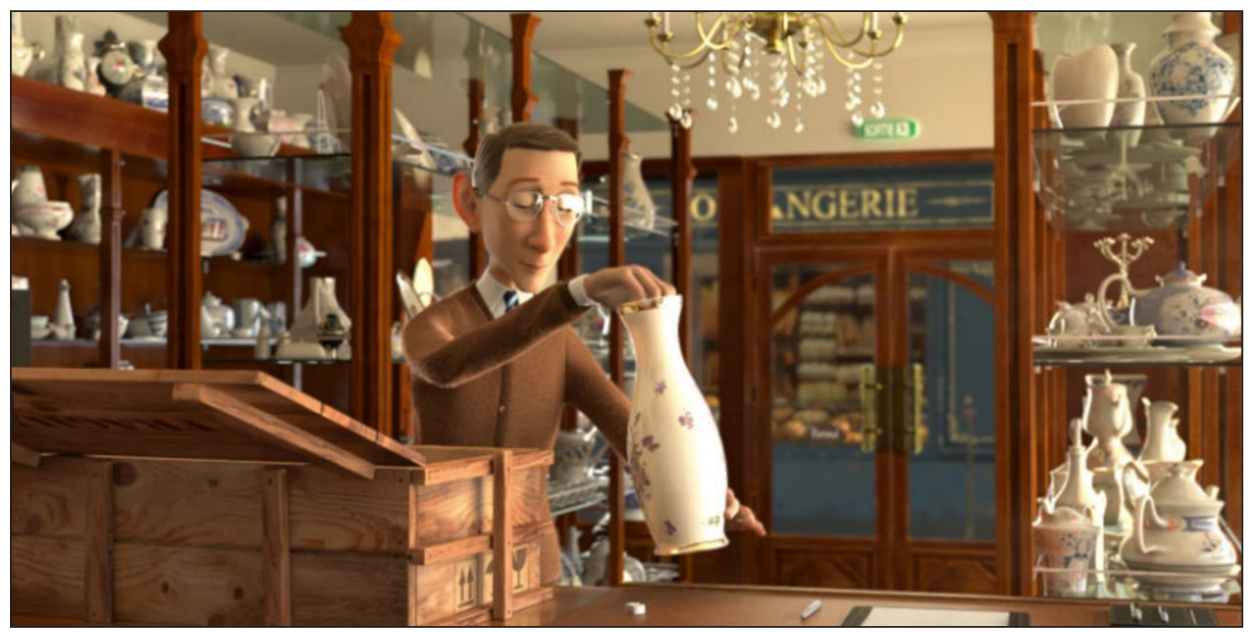

Fonte: Comme un éléphant dans un magasin de porcelaine (YouTube).

O curta Comme un éléphant dans un magasin de porcelaine ${ }^{4}$ compõe o nosso movimento formativo para provocar as redes de conversação e fazer movimentar

\footnotetext{
${ }^{4}$ Produzido em 2017 por Louise Chevrier, Luka Fischer, Rodolphe Groshens, Marie Guillon, Estelle Martinez, Benoit Paillard e Lisa Rasasombat, da École Supérieure des Métiers Artistiques (Esma). (Disponível em: https://www.youtube.com/watch?v=h_aC8pGY1aY\&ab_channel=ESMAMovies).
} 
o pensamento, desestabilizando certezas e criando outros possíveis. O cenário é uma loja cheia de porcelanas, objetos delicados, e a figura do vendedor, profissional muito organizado, trata cada peça com cuidados de esteta, até aparecer a figura do elefante, animal enorme, que destoa daquele espaço tão pequeno e delicado. Ao mesmo tempo que o vendedor se assusta com o tamanho do elefante naquele lugar pequeno - inóspito para um animal de tamanha proporcionalidade -, o elefante também se incomoda por estar ali. A desproporcionalidade entre o tamanho do elefante e a delicadeza do lugar com suas frágeis porcelanas faz o vendedor levar um susto, ao deparar-se com o enorme animal dentro da loja. Naquele instante, com o susto, o senhor arremessa para o alto um vaso de porcelana que estava em suas mãos, já esperando que a peça cairia ao chão, estilhaçando-se em pequenos pedaços. Mas, atônito, vê o elefante alcançar o frágil objeto ainda em movimento, no ar, entregando-Ihe em suas mãos, delicadamente.

Temos um caos no território. Há uma espécie de "bagunça" não propositiva, que força um regime de pensamento e convida-nos a experimentar a potência disruptiva de um acontecimento louco nos movimentos aberrantes que os personagens são constrangidos a fazer. A partir de então, eles começam a se entender, surgindo entre eles uma relação afetuosa. Nessa relação de confiança entre ambos, são criadas possibilidades para que o elefante se mova entre as prateleiras de vidro com as frágeis porcelanas, para, assim, poder sair da loja.

O que queremos com o curta nesse encontro? Experimentar com professores e professoras as forças intensivas desse disparador para pensar as linhas de segmentaridade dura que nos atravessam, mas que são desterritorializadas pelos movimentos desse fora que chega e altera tudo dentro. Como dizem Delboni, Gonçalves e Reis (2020, p. 353), "[...] no encontro com as linhas de segmentaridade dura ou molar, que produz uma territorialidade, organização, significado, estratificação, somos atravessados pelo arroubo das linhas de desterritorialização que causa uma ruptura". Como olhar para si e pensar nessa multiplicidade que "bagunça" uma estrutura arborescente e nos movimenta para uma vida rizomática, que já começa pelo meio como um ponto de uma linha que se vai derivar em múltiplos outros caminhos?

Nesse encontro com o curta, com professores e professoras, com porcelanas, elefante e vendedor, queremos entrar em relação para produzir experimentação e, assim, fazê-los oscilar, conectar, produzir fluxos e ressonâncias. Queremos 
O encontro com os signos artísticos do cinema produzindo movimentos aberrantes nas redes de conversação com professores e professoras

provocar agenciamentos.

Um agenciamento é isso. Não apenas a reunião ou o ajuntamento de corpos, mas o que acontece aos corpos quando eles se reúnem ou se juntam, sempre sob o ponto de vista de seu movimento e de seus mútuos afectos. Não se trata apenas de uma questão de soma, mas de encontro ou de composição. Não apenas a simples justaposição assinalada pela conjunção 'e', mas a complexa combinação implicada pela partícula 'com'. 'Isto e aquilo' é bom, mas 'isto com aquilo' é ainda melhor. (TADEU, 2002, p. 56).

Em uma articulação de forças, somos movimentados pelos efeitos que as imagens-cinema provocam em nós. O que elas nos dão a pensar? Para isso, instauramos redes de conversação sobre a experimentação: O que passou? O que (de) formou, (des)locou? Que diferença, depois da experimentação, manifesta-se em cada um com mais força? Qual foi a metamorfose operada, ao entrar em relação com o curta? Como a violência no pensamento nos faz reinventar e movimentar a vida em sua potência?

Imagem 2 - O susto, o arroubo, o inusitado

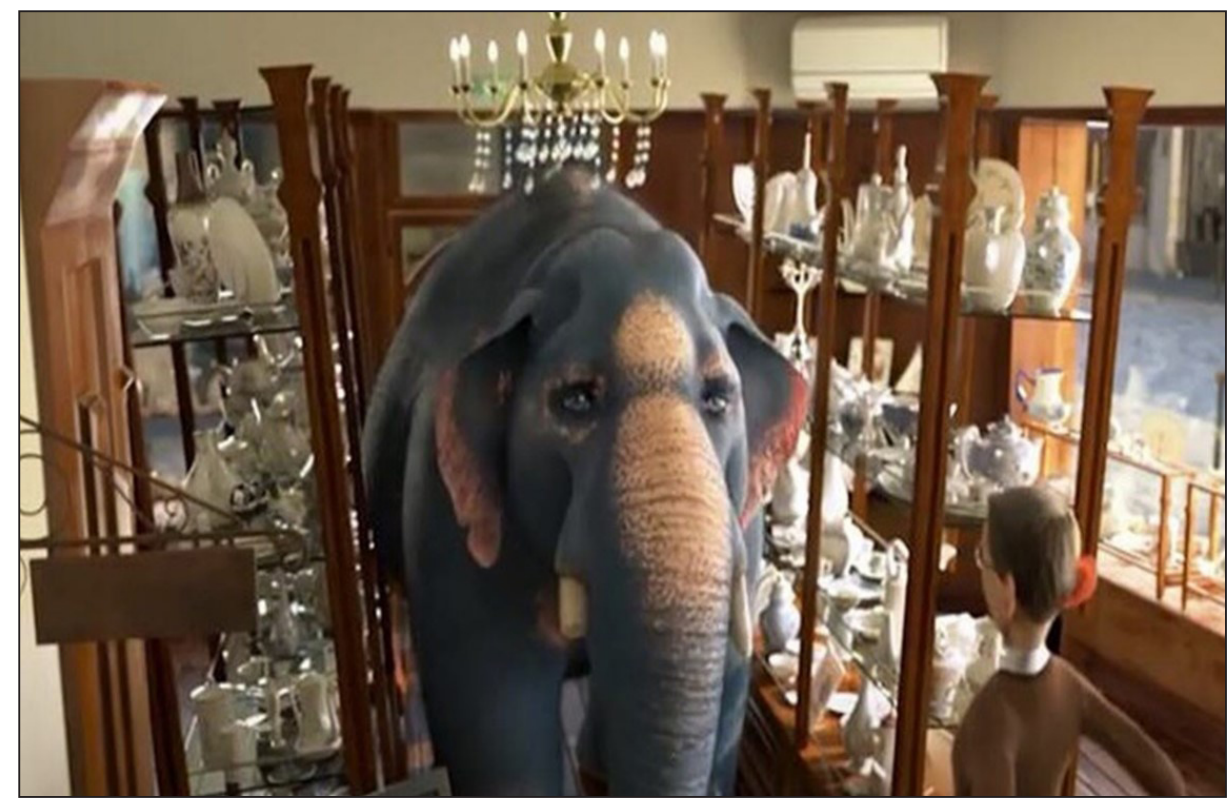

Fonte: Comme un éléphant dans un magasin de porcelaine (YouTube). 
E aqui nos colocamos em relação às redes de conversação ${ }^{5}$ com professores e professoras, convidando-os a dar língua aos afetos que pedem passagem no encontro com o curta:

A gente pode ver que o significado que as coisas têm para um, não tem para o outro e como isso afeta... A loja tinha um grande significado para o vendedor, com aquela organização toda. O vendedor mantinha uma organização para manter tudo aquilo protegido e, de repente, vem o elefante, para quem aquele espaço não tinha o mesmo significado. Mas foi na relação que eles conseguiram criar confiança e possibilidade de buscar uma saída para o animal. Eu penso nas nossas relações... às vezes a gente coloca tanto sentido em algo, mas que não tem para o outro... E a gente tem que rever. Na educação isso tem muito. A gente tem uma ideia de educação, de docência, de currículo, a gente quer ter controle de tudo. Mas, às vezes, para o aluno aquilo não afeta, não é significativo ou não tem sentido.

E o elefante colocou para o vendedor uma nova visão daquele espaço da loja. Ele abriu um espaço entre as prateleiras... É esse espaço que a gente tem que dar para receber esse novo. Com a pandemia, nós recebemos um baque... Estávamos todos dentro das gavetinhas, todo mundo arrumadinho, tendo um trabalho direcionado, planejado, e agora a gente tem esse mesmo movimento do elefante, o momento violento que a pandemia nos causou.

É um desafio estar aberto para o novo, para acolher. As nossas crianças também vêm como esse elefante, todas cheias de movimentos, de ansiedades, como nós. O acolhimento é fundamental. Receber o novo, abrir espaços para novas aprendizagens, novos conhecimentos, novas trocas e respeitar a história de cada um. Primeiro foi o susto: "O que é isso? Que gigante é esse invadindo a minha loja, a minha zona de conforto?".

Vemos o personagem vendedor como um corpo organizado que é constrangido pela presença do elefante, o qual desestabiliza a sua organização. Isso nos faz pensar nas ideias que temos em relação à nossa maneira de agir e de existir no mundo. Uma determinada maneira fechada de pensar, que se abre à força de alguma desrazão e nos leva a pensar sobre a nossa própria experiência nos movimentos de formação para dar sentidos outros, para inventar outros saberes sobre a própria existência, docências, infâncias, escolas, currículos.

\footnotetext{
${ }^{5}$ Entendemos as redes de conversação como agenciamentos coletivos de enunciação; portanto, a força não está na identificação do sujeito que fala, mas nas ressonâncias que o conjunto das falas provoca.
} 
O encontro com os signos artísticos do cinema produzindo movimentos aberrantes nas redes de conversação com professores e professoras

A divergência, a desarmonia, o desacordo passam a se relacionar. Há uma positividade da divergência que é difícil compreender. Uma divergência, um desacordo que não quer ser resolvido, que não pede um apaziguamento. Cada termo é afirmado sem medida, sem resolução, sem conclusão. E é nesse movimento que diverge o tempo todo, faz provocar afecções reveladoras de "potência de ação coletiva" (CARVALHO, 2011), para pensar na força dos indivíduos e dos grupos que se encontram em relação, para produzirem, por meio dos agenciamentos, formas e forças comunitárias e melhorarem os processos da aprendizagem e da criação nas coletividades locais, assim como no interior de redes cooperativas de todo tipo (CARVALHO, 2011).

Com professores e professoras, vemos que o curta provoca discussões em torno do novo, do inusitado, do inesperado que irrompe, trazendo outras possibilidades, a abertura de espaços, a saída de uma organização preestabelecida para provocar mudanças. E algumas falas trazem a força das crianças nesse movimento que provoca abalos e rupturas. "As crianças trazem para a gente, muitas vezes, a possibilidade de pensar e agir diferente. Por exemplo, a dificuldade de uma criança no processo de aprendizagem nos leva a buscar alternativas que, antes, a gente não imaginava".

As crianças, em movimentos desterritorializantes, instauram novas possibilidades para a docência, trazendo para a prática pedagógica diferentes sentidos para currículos. Entendidos para além de caminhos lineares formatados para serem seguidos, os movimentos aberrantes impelem professores e professoras a pensar os currículos como campos de heterogeneidade, constituídos por saberes diversos e com capacidades variadas de múltiplos sentidos e inúmeras possibilidades por quem vive a Educação Infantil. Um currículo, segundo Paraíso (2009), está sempre cheio de ordenamentos, de linhas fixas, de corpos organizados, de identidades majoritárias, mas está também sempre cheio de possibilidades de rompimento das linhas do ser, de contágios que podem nascer e se mover por caminhos desconhecidos, outros possíveis que podem desenvolver-se de formas particulares. "Fico pensando nas crianças que muitas vezes nos tiram o chão, nos abalam de alguma forma em nossas aulas".

A relação da diferença entre o vendedor e o elefante, no curta, produz nos professores e nas professoras a necessidade de conversar como as diferenças se apresentam nos cotidianos escolares. "A gente precisa refletir como a gente age 
diante do diferente. A gente pode reagir de várias formas. Mas é preciso refletir o que esse diferente pode produzir, como novas formas de relações ou outras formas de afetar". As redes de conversação demonstram a força de se falar por afetos, intensidades, experimentações, abrindo-se às multiplicidades, aos fluxos, às problematizações: "Como a gente compõe com o diferente, como a gente compõe com o inusitado, com aquilo que a gente não espera, com aquilo que foge da nossa organização? E como a gente pode transformar esse encontro em um encontro de bons afetos a partir da diferença?".

Fazendo relação com o cotidiano escolar: Quantas vezes a gente encontra com o inusitado? A última coisa que a gente poderia imaginar é que em uma linda loja de porcelanas a gente ia encontrar um elefante. E nada mais diferente do que a leveza das porcelanas, a delicadeza com o elefante. A gente poderia pensar a escola, os currículos, esse encontro com o inusitado, com aquilo que a gente jamais esperava e a forma que a gente vai buscar para compor com esse inusitado.

Quantas vezes também a gente, no coletivo escolar, se depara com o diferente, com colegas que pensam diferente, colegas que tem outra prática pedagógica. O movimento do pensamento é produzido a partir das diferenças.

$O$ coletivo escolar é cheio disso. As pessoas são diferentes. E como a gente pode compor com esse diferente, a partir desse encontro com o inusitado? Vamos colocar as porcelanas para balançar com o nosso pensamento, para mudar, transformar.

Eu vejo aqui a importância do ouvir para você ter a possibilidade de refletir, para mudar de opinião. Cada um tem a sua percepção do elefante... Eu pensei na pandemia que virou a minha vida de cabeça para baixo. E eu aprendi a lidar com situações que eu nunca tinha pensado.

Pensar o encontro com as imagens como potência para movimentar o pensamento de professores e professoras possibilita novos movimentos no processo de aprenderensinar, novas sensações e questionamentos que provocam fissuras nas verdades "[...] constituídas/produzidas para as escolas, para as infâncias, para as docências, para os currículos, para as pesquisas em educação" (SILVA, 2019, p. 285).

É o movimento no pensamento que problematiza os currículos, as docências, as infâncias, entendendo-os como processos gestados no cotidiano escolar no qual professores e professoras, como comunidade de afetos, efetuam a potência de 
vida política nos coletivos de que fazem parte. Quando falamos de comunidade de afetos, com base em Carvalho (2011), não estamos falando de um lugar-comum que revela pessoas pensando iguais, mas pensando nas possibilidades de entrar em relação. Trata-se de "[...] outra lógica, ou seja, a que não diz o que é de modo universal ou o que deve ser, mas o que força a comunidade a se transformar e que faz seu devir sempre aberto e permeável, logo, sempre outro 'possível'-1" (CARVALHO, 2011, p. 86).

Com Carvalho (2011), queremos pensar na potência da alegria de aprender, no prazer de criar nas salas de aulas - também remotas - das escolas e, para isso, pensar os currículos como um acontecimento vivido nele mesmo, pensando-os como aquilo que "[...] muda à medida que nos envolvemos com ele, refletimos sobre ele, consideramos sua complexidade tecida em rede de conversações e agimos em direção à sua realização, buscando nos afetos e afecções a potência inventiva de um currículo não burocratizado e normalizado" (CARVALHO, 2011, p. 86).

Professores e professoras, no encontro com o curta, compartilham afetos e afecções, fazendo fluir movimentos de corpos que trazem suas marcas dos afetos produzidos com outros corpos no mundo, afugentando ou produzindo mais (desa) sossegos e experimentando a travessia de um território ruído. Os agenciamentos coletivos de enunciação expressam a invenção de um espaço, um tempo, um lugar, um encontro formativo no qual são provocados movimentos aberrantes para delinear deslocamentos outros,

[...] algo parecido com o traçado de um devir, que implica, ao mesmo tempo, experimentá-lo de diversos modos. Sem começo e sem fim. Um meio denso de estar atento à diferença e de afirmarmos, cada vez mais, a potência de nos diferenciarmos daquilo que somos. Devir é um meio e uma singularidade, não de nos diferenciarmos dos outros, mas sobretudo de nós mesmos. 0 desafio de saber encontrar no acontecimento aquilo que nos força a pensar e nos tira da repetição do mesmo, impulsionando-nos para o próprio ato da potência de existir. (DIAS; PELUSO; BARBOSA, 2013, p. 225).

Assumindo a ideia de "potência de ação coletiva" (CARVALHO, 2011), entendemos que professores e professoras produzem movimentos aberrantes quando se colocam em relação, para engendrarem, por meio dos agenciamentos, redes cooperativas nas quais fazem expandir a vida. 


\section{REVERBERAÇÕES E RESSONÂNCIAS... PARA NÃO CONCLUIR...}

Buscamos, aqui nesta escrita, apresentar uma experimentação provocada em processos de formação inventiva - com professores e professoras - no encontro com o signo artístico do curta Comme un éléphant dans un magasin de porcelaine, para produzir movimentos aberrantes em redes de conversação.

As afeç̧ões e os afetos que o curta provoca no pensamento dos professores e professoras trazem-nos a ideia de que os diferentes modos de subjetivação não se limitam aos sujeitos, mas aos acontecimentos em que estão envolvidos. Isso nos remete ao processo de transformação simultâneo do dentro e do fora em Deleuze, que escapa da ideia de um interior separado das relações que os sujeitos estabelecem cotidianamente. Temos uma interioridade constituindo-se a partir dos desdobramentos do exterior que nos afeta o tempo todo. "O lado de fora não é um limite fixo, mas uma matéria móvel, animada de movimentos peristálticos, de pregas e de dobras que constituem um lado de dentro: nada além do lado de fora, mas exatamente o lado de dentro do lado de fora" (DELEUZE, 1991, p. 104).

Vemos que os movimentos aberrantes produzidos como experimentação se abrem para outras maneiras para pensar as relações com o mundo e alterar um corpo organizado com prateleiras, e porcelanas, e planejamentos, e prescrição, e pandemia. Entendemos, com a inusitada presença do elefante, que um corpo todo organizado nos aprisiona em determinadas funções, mas precisamos abrir as prateleiras, as linhas que nos constituem, para nos colocarmos em relação com um modo novo de existência produzido com os movimentos aberrantes do pensamento. Isso nos faz pensar numa vida que

[...] não se limita a produzir organismos, nem assume invariavelmente uma forma orgânica. Pelo contrário, os movimentos aberrantes atestam uma 'vida inorgânica' que atravessa os organismos e ameaça sua integridade; uma vida tão indiferente aos corpos que atravessa quanto aos sujeitos que transtorna. Chega-se ao ponto em que a vida [...] leva o sujeito a experimentação no limite do insuportável. (LAPOUJADE, 2015, p. 22).

O curta, então, é o que desterritorializa a nossa relação com os territórios preestabelecidos da subjetividade. Não cabe a constituição de um sujeito não pensante. Temos um território onde o constrangimento é inevitável. E é esse constranger que se move para dentro da loja e desorganiza tudo para re-des-organizar de outro modo. Temos pensamentos movendo-se para além das estruturas coesas 
e forçando a implosão da forma, do todo organizado, rompendo com a normatividade para não se deixar reduzir àquilo que se espera. Os movimentos aberrantes fazem liberar a potência da vida, engendrando modos outros de subjetivação e criando novas relações, porque se abre para um corpo múltiplo, um corpo cheio de intensidades, o qual instaura mundos onde outros pensamentos são possíveis, outras docências, outras infâncias, outros currículos, outras vidas...

\section{REFERÊNCIAS}

CARVALHO, Janete Magalhães. Currículo e práticas cotidianas em redes de conversações: o falar. In: LIMA, Maria do Socorro Lucena; CAVALCANTE, Maria Marina Dias; SALES, José Albio Morreira; FARIAS, Isabel Maria Sabino (Org.). Didática e a prática de ensino na relação com a escola. Fortaleza: EdUECE, 2011.

CARVALHO, Janete Magalhães. O cotidiano escolar como comunidade de afetos. Petrópolis/Brasília: CNPq, 2009.

DELEUZE, Gilles. Diferença e repetição. Tradução de Luiz Orlandi e Roberto Machado. Rio de Janeiro/São Paulo: Paz e Terra, 2018.

DELEUZE, Gilles; GUATTARI, Félix. Mil platôs: capitalismo e esquizofrenia. Tradução de Peter Pál Pelbart e Janice Caiafa. São Paulo: Ed. 34, 2012. V. 5.

DELEUZE, Gilles. Proust e os signos. 2. ed. Tradução de Antonio Piquet e Roberto Machado. Rio de Janeiro: Forense Universitária, 2003.

DELEUZE, Gilles. Conversações. Tradução de Peter Pál Pelbart. São Paulo: Ed. 34, 1992.

DELEUZE, Gilles. A dobra: Leibniz e o barroco. Campinas, SP: Editora Papirus, 1991.

DELBONI, Tânia Mara Zanotti Frizzera; GONÇALVES, Camilla Borini Vazzoler; REIS, Eliana Aparecida de Jesus. As imagens-cinema como máquinas de guerra do pensamento: currículos e docências e... In: CARVALHO, Janete Magalhães; SILVA, Sandra Kretli; DELBONI, Tânia Mara Zanotti Guerra Frizzera (Org.). Currículo e estética da arte de educar. Curitiba: CRV, 2020.

DIAS, Rosimeri de Oliveira. Formação inventiva de professores e políticas de cognição. Informática na Educação: Teoria \& Prática, Porto Alegre, v. 12, n. 2, p. 164-74, jul./dez. 2009. 
DIAS, Rosimeri de Oliveira; PELUSO, Marilena dos Reis; BARBOSA, Márcia Helena Uchôa. Conversas entre micropolítica e formação inventiva de professores. Mnemosine, [s.l.], v. 9, n. 1, p. 224-37, 2013.

KASTRUP, Virgínia. Aprendizagem, arte e invenção. Psicologia em Estudo, Maringá, v. 6, n. 1, p. 17-27, jan./jun. 2001.

LAPOUJADE, David. Deleuze e os movimentos aberrantes. Tradução de Laymert Garcia dos Santos. São Paulo: Editora n-1, 2015.

SILVA, Sandra Kretli. As imagens-cinematográficas como força que impulsiona o devirpensamento no cotidiano escolar. Revista Teias, Rio de Janeiro, v. 20, n. 59, p. 283-300, out./dez. 2019.

TADEU, Tomaz. A arte do encontro e da composição: Spinoza + Currículo + Deleuze. Educação \& Realidade, Porto Alegre, RS, v. 27, n. 2, p. 47-57, jul./dez. 2002.

TÓTORA, Silvana. Quid vitae? Uma política dos movimentos aberrantes. Aurora: Revista de Arte, Mídia e Política, São Paulo, v. 9, n. 27, p. 108-13, out. 2016/jan. 2017.

\section{Sobre os autores:}

Tânia Mara Zanotti Guerra Frizzera Delboni: Doutora em Educação pela Universidade Federal do Espírito Santo (UFES). Professora adjunta do Departamento de Teorias Educacionais e Práticas de Ensino da UFES; do Programa de Pós-Graduação em Educação (PPGE); e do Programa de Pós-Graduação Mestrado Profissional em Educação. E-mail: taniadelboni@terra.com.br, Orcid: https://orcid.org/0000-0003-3950-0427

Carlos Pereira de Melo: Mestre em Educação pela Universidade Federal do Espírito Santo (UFES). Professor da Rede Municipal de Educação de Serra, ES, e professor da Educação Infantil da Rede Municipal de Cariacica, ES. E-mail: carlosp.melo40@gmail.com, Orcid: http://orcid.org/0000-0002-3739-7692 